\title{
Dietary Patterns and the Risk of Non-Hodgkin Lymphoma: The Multiethnic Cohort
}

\author{
Eva Erber, MS, Gertraud Maskarinec, MD, PhD, Jasmeet K. Gill, PhD, Song-Yi Park, PhD, \\ and Laurence N. Kolonel, MD, PhD \\ Cancer Research Center of Hawai'i, University of Hawaii, 1236 Lauhala Street, Honolulu, HI \\ 96813
}

\begin{abstract}
We examined dietary patterns and NHL risk in the Multiethnic Cohort which includes more than 215,000 Caucasians, African-Americans, Japanese-Americans, Native Hawaiians, and Latinos aged 45-75 at baseline. All subjects completed a validated food frequency questionnaire. After a median follow-up time of 10 years, we identified 939 incident NHL cases through linkages with tumor registries. Three patterns, "Vegetables", "Fruit and Milk", and "Fat and Meat", were analyzed using Cox regression. None of the patterns was significantly associated with NHL risk in the total population. However, the "Vegetables" pattern was inversely related to risk in Caucasian women with a hazard ratio of $0.56\left(P_{\text {trend }}=0.04\right)$ and the "Fat and Meat" pattern was associated with a 5-fold higher follicular lymphoma risk in men $\left(P_{\text {trend }}=0.03\right)$. The lack of significant results in men and women indicates a limited role of diet in NHL etiology, but dietary patterns might have ethnic- and subgroup-specific effects on NHL.
\end{abstract}

\section{Keywords}

Non-Hodgkin Lymphoma; dietary patterns; prospective studies; ethnicity

\section{INTRODUCTION}

Non-Hodgkin Lymphoma (NHL) was the fifth most common cancer in the US in 2007 and the incidence rate almost doubled from 1973 to 1994 [1;2]. Immune dysfunction is considered as the underlying basis of lymphoma development, but immunosuppressive states (e.g., HIV infection or organ transplants) only partially explain the increase in NHL cases. Caucasians have a 50\% higher incidence rate than African-Americans and Asians and a 15\% lower risk than Latinos [1]. There is also evidence that the NHL incidence rate is almost twice as high among American-Asians compared to Asians living in their country of origin [2]. Therefore ethnic-specific differences in lifestyle factors might influence NHL risk.

Because diet affects hormonal and metabolic responses to cell growth and survival, nutritional factors might influence NHL risk. Excessive intake of meat may contribute to lymphoma through increased, chronic antigenic stimulation and immune system impairment [3;4]. A reduction in fat intake might improve immune responses by enhancing lymphocyte

Address for correspondence: Eva Erber, DI, MS, Cancer Research Center of Hawaii, 1236 Lauhala Street, Honolulu, HI 96813 , Phone: (808) 564-5839, FAX: (808) 586-2982, eerber@crch.hawaii.edu.

DECLARATION OF INTEREST: The authors report no conflicts of interest. The authors alone are responsible for the content and writing of the paper. 
proliferation and natural-killer-cell activity [5]. NHL risk may also be affected by reactive oxygen species (ROS), which might alter immune responses by damaging DNA and lipid membrane structures in immune cells but the antioxidant properties of dietary fruits and vegetables can intervene in these pathways [6-9].

Dietary patterns are an innovative approach to describe overall dietary behavior rather than single food items which might be highly correlated and exert interactive and synergistic effects [10;11]. In this study, the association between three dietary patterns, "Fat and Meat", "Vegetables", and "Fruit and Milk" and NHL risk was analyzed by ethnicity and NHL types in a large prospective cohort in the US.

\section{METHODS}

\section{Study Population}

The Multiethnic Cohort (MEC) was assembled in Hawaii and Los Angeles between 1993 and 1996 [12]. Subjects from five ethnic-racial groups (Caucasian, African-American, Latino, Japanese-American, and Native Hawaiian) aged 45-75 years were recruited using drivers' license files supplemented with other sources. Each person received up to three mailings of a 26-page, self-administered questionnaire that included demographics, diet, and other risk factors for cancer. Response rates varied from $20 \%$ in Latinos to $49 \%$ in JapaneseAmericans and yielded a highly representative group when comparing the cohort distributions across educational levels and marital status with corresponding census data [12]. After excluding 13,992 individuals who were not part of the main ethnic groups, 8,264 subjects who reported a daily intake of $<500$ or $>8,000$ calories or who completed less than 5 pages of the FFQ, and 513 people with prior NHL, 87,078 men and 105,972 women were part of the analysis. The Institutional Review Boards at the University of Hawaii and at the University of Southern California approved the study.

\section{Identification of Non-Hodgkin Lymphoma Cases}

Annual linkages of the cohort to the Hawaii Tumor Registry, the Los Angeles County Cancer Surveillance Program, and the State of California Cancer Registry identified incident NHL cases. These SEER registries follow the same rules and quality control [13]. Death certificates and the National Death Index were used to determine mortality. NHL was classified according to the adaptation of the World Health Organization classification for epidemiologic studies using the International Classification of Disease Oncology version 3 [13;14]: DLBCL (9675-9680, 9684), FL (9690, 9691, 9695, 9698), CLL (9823) or SLL (9670), and T-cell lymphoma (9700-9719, 9827, 9831, 9948).

\section{Food Frequency Questionnaire}

The calibrated quantitative food-frequency questionnaire (QFFQ) queried the usual eating habits during the last year and included specific food items characteristic of each of the five ethnicities studied [15]. The questionnaire included 8 frequency categories for food (highest category was $\geq 2$ times/day) and 9 for beverages (highest category was $\geq 4$ times/day) together with 3-4 different portion sizes. Nutrients were determined using a customized and ethnic-specific food composition table based on the United States Department of Agriculture nutrient database and additional laboratory analyses performed in Hawaii [12]. Food Guide Pyramid servings were computed for each cohort member [16]. Subjects who reported extreme energy, fat, protein, or carbohydrate intake outside the mean \pm 3 relative standard deviation were excluded. 


\section{Dietary Patterns}

The dietary patterns in the MEC were previously identified using Factor Analysis [16]. This method describes several variables and their relationship in terms of a smaller number of underlying factors. Dietary variables that did not show normal distribution were transformed using Box-Cox transformation. Alcohol had to be excluded as it did not meet the normality assumption. After randomly dividing the study population into two groups, the analysis was performed using exploratory factor analysis with orthogonal rotation to determine dietary patterns in one group and confirmatory factor analysis to validate the factor model in the other group. The model provided an acceptable fit as determined by the overall goodness-offit statistics and a more detailed fit assessment. Variables were only kept in the analysis if the factor loading for the variable was higher than 0.55 and if the factor had at least three variables loaded. Finally, the validated exploratory factor analysis was applied to the overall cohort to obtain factor scores for each participant. Through this analysis three distinct dietary patterns were identified (Figure 1): "Vegetables" was characterized by high loadings of vegetables and some fruits, "Fat and Meat" included by high amounts of discretionary fat, meat, eggs, and cheese, and the pattern "Fruit and Milk" was characterized by high loadings on milk, yogurt, cheese, and fruits. Native Hawaiians and Latinos were more likely to have high scores on the "Fat and Meat" pattern and Native Hawaiians and Japanese-Americans had higher scores in the "Vegetables" pattern, whereas Latinos and Caucasians showed a stronger association with the "Fruit and Milk" pattern [16].

\section{Statistical Methods}

The risk of NHL due to the three dietary patterns was analyzed using Cox proportional hazards regression models to estimate relative risk as hazard ratios (HR), including 95\% confidence intervals (CI) [17]. The follow-up ended at the earliest of the following events: diagnosis of NHL, death, or on December 31, 2003. The models were stratified by follow-up group $(\leq 2,2-5$, and $>5$ years) and included age as the time metric. Because of previously reported associations with NHL, all models were adjusted for age at cohort entry, ethnicity, education, alcohol intake, and total energy intake [18]. Age at first live birth was included as a covariate in the models among women because log-likelihood tests indicated a significant improvement of the models, while there was no evidence that other lifestyle or reproductive variables improved model fit. The proportional hazards assumption as tested by examining Kaplan-Meier survival curves and Schoenfeld residuals was not violated. Exposure to dietary patterns was analyzed as quartiles with different cutpoints for men and women. Sexspecific tertiles were used for NHL subgroup and ethnic specific analyses due to the small number of NHL cases. Ordinal variables representing the median values for each quartile were used to test for linear trends. The small number of cases did not allow any analyses for Native Hawaiians, marginal lymphoma, or T-cell NHL. All statistical analyses were performed using the SAS software, version 9.1 (SAS Institute, Inc., Cary, NC).

\section{RESULTS}

The 939 NHL cases tended to be older and were more likely to be Caucasian than the noncases (Table I). DLBCL was common in all ethnic groups (Japanese 37\%, Latinos 45\%, Caucasians 25\%, African-Americans 24\%, and Native Hawaiians 34\%), while the percentage of SLL/CLL cases was highest in Caucasians (32\%), African-Americans (28\%), and Native Hawaiians (24\%) and low in Japanese (10\%) and Latinos (14\%). FL and T cell tumors were the least common NHL types. The median follow-up of this study was 10 years.h 
None of the dietary patterns was significantly associated with NHL risk in men and women overall (Table II). Therefore, we focused on ethnic- and NHL subgroup-specific results which are unique contributions of the MEC.

After stratification by ethnic group, high scores for the "Vegetables" pattern were significantly inversely associated with NHL risk in Caucasian women with HR $=0.56$ (95\% CI: 0.33-0.95) when comparing the highest tertile to the lowest $\left(P_{\text {trend }}=0.04\right)$ (Figure 2). This dietary pattern also slightly lowered risk, although not statistically significant, in Japanese women. In contrast, Latino women experienced a non-significantly positive association between the pattern "Vegetables" and NHL risk. "Fat and Meat" slightly elevated NHL risk in Caucasian, Japanese, and Latino men. Latino women, however, experienced beneficial effects related to the "Fat and Meat" pattern. Nevertheless, these results were not statistically significant. "Fruit and Milk" did not show any significant associations in any ethnic group, but indicated a non-significant inverse relation with NHL risk in African-American men and women, while it non-significantly elevated risk in Caucasian women.

Statistically significant results were also limited in the NHL subgroup analysis (Table III). The pattern "Vegetables" slightly elevated risk for SLL/CLL in men, although not statistically significant. "Fat and Meat" significantly elevated FL risk more than 5 times in men (HR=5.16; 95\% CI: $1.33-20.00 ; P_{\text {trend }}=0.03$ ), which is, however, based on only 12 cases in the highest quintile, and was non-significantly positively associated with DLBCL risk in women. This pattern, however, seemed to lower DLBCL risk in men and FL risk in women, both not statistically significant. Finally, the factor "Fruit and Milk" was inversely associated with SLL/CLL risk in women with a HR=0.16 (95\% CI: 0.05-0.44) for the second tertile and non-significantly lowered risk for SLL/CLL in men and DLBCL and FL in women.

\section{DISCUSSION}

None of the patterns was significantly associated with NHL risk in the total population. However, some noteworthy findings include an inverse association between the "Vegetables" pattern and NHL risk in Caucasian women, while the pattern "Fat and Meat" showed a positive association with FL in men. Finally, "Fruit and Milk" was inversely associated with SLL/CLL in women. However, these results might be due to chance.

To our knowledge, no previous study has examined the effects of dietary patterns on NHL risk. In addition, the literature on different ethnic groups and NHL subgroups is limited. The protective effect of the factor "Vegetables" on Caucasian women is consistent with several studies [6;19-21] which examined vegetables as a food group. Antioxidants, flavonoids, folate, and fiber contained in vegetables [22-24] may prevent reactive oxygen species from damaging DNA and improve immune function [23;25]. But the suspected carcinogen nitrate and pesticides in vegetables and legumes may adversely affect NHL risk [6].

The finding of elevated FL risk associated with the pattern "Fat and Meat" in men agrees with previous studies on red meat and FL [23;26]. The positive relationship between "Fat and Meat" and FL in men might be due to its high amounts of saturated fat, which may alter immunocompetence and immune system impairment through elevated levels of NF-кB and proinflammatory factors [22]. Furthermore other ingredients, such as hormones and antibiotics contained in meat, might have adverse effects on NHL [27]. The inconsistent associations of "Fat and Meat" with NHL risk might be observed because on the one hand, mutagenic compounds (heterocyclic amines and polycyclic aromatic hydrocarbons) are 
formed when meats are cooked at high temperature, but, on the other hand, oncogenic viruses and other contaminants may be destroyed by heat.

The beneficial effect of the "Fruit and Milk" pattern on SLL/CLL in women was also observed in a previous study on milk and SLL [28]. However, other studies found an elevated SLL/CLL risk associated with fruits and dairy products $[23 ; 28]$. The cancerpreventive and carcinogenic properties of fruits are similar to vegetables, as described above. Possible biological mechanisms explaining the inconsistent effect of dairy products on NHL are that these foods contain large amounts of fat and protein, which are considered risk factors for NHL, but are also a good source of riboflavin and vitamin A, which may be protective [24].

This is the first report on dietary patterns in relation to NHL risk. The small number of previous studies on diet and NHL focused on single food items. However, people do not consume individual foods, but whole meals composed of many different nutrients which are highly correlated and exert interactive and synergistic effects [10;29]. Dietary patterns have been shown to be a valid tool to improve the understanding of the role of diet in chronic disease development [30;31]. This study included subjects from different ethnic backgrounds with a wide variety of dietary exposures. The different amounts and types of foods consumed and, therefore, the differences in factor scores might have accounted for some of the inconsistent results between ethnic groups. After 7 years of follow-up an outmigration rate of only $3.7 \%$ (2.5\% of California participants moved to Hawaii and $4.9 \%$ of Hawaii participants moved to California) was observed [12]. Another strength of this study was the use of SEER tumor registries that ensure accurate NHL classification despite the many different institutions involved in diagnosing the cases. It is likely that the majority of pathologic diagnoses were accurate; all NHL cases occurred after the implementation of the WHO classification [13].

This analysis was limited by the number of cases for the subgroup analysis, but the overall sample size of our 939 cases was larger than most other studies of diet and NHL. Also, the median follow-up of 10 years is still relatively short. Analyses of Native Hawaiians, T-cell NHL, and marginal NHL were not possible because some tertiles involved less than 15 cases. Nevertheless, this study is one of few studies that explored the ethnic and subgroupspecific association between diet and NHL. Genetic susceptibility might be responsible for differential effects in ethnic groups and genetic investigations will provide new insights [32]. The different findings across ethnic groups might also be due to differences in subtypes or nutritional exposure. Despite certain commonalities for NHL subtypes, dietary components may exert different effects on the etiology of the diverse subgroups [33]. Due to multiple comparisons, significant results might be false positive findings. Measurement error in the FFQ was likely to have occurred, which might have attenuated the risk estimates. Information on some crucial confounders, such as pesticides or occupational exposure [32], was not available for this analysis.

The findings of this research offer little support for the hypothesis that NHL risk associated with dietary patterns differs between ethnic groups and NHL subgroups because the significant findings may have been due to chance. Therefore we conclude that the role of diet in NHL etiology may be limited or difficult to detect with current dietary assessment methods.

\section{Acknowledgments}

The Multiethnic Cohort was supported by the National Cancer Institute (R37 CA54281). JG was supported by a postdoctoral fellowship (R25 CA 90956). The Hawaii Tumor Registry is supported by the SEER contract N01PC-35137. 


\section{References}

1. Parkin, DM.; Whelan, SL.; Ferlay, J.; Teppo, L.; Thomas, DB. Cancer Incidence in Five Continents. Vol. VIII. Lyon: International Agency for Research on Cancer; 2003.

2. Northern California Cancer Center. Non-Hodgkin's Lymphoma. 2008

3. Davis S. Nutritional factors and the development of non-Hodgkin's lymphoma: a review of the evidence. Cancer Res Oct;1992 52(19 Suppl):5492s-5495s. [PubMed: 1394161]

4. Zheng T, Holford TR, Leaderer B, Zhang Y, Zahm SH, Flynn S, Tallini G, Zhang B, Zhou K, Owens PH, Lan Q, Rothman N, Boyle P. Diet and nutrient intakes and risk of non-Hodgkin's lymphoma in Connecticut women. Am J Epidemiol Mar;2004 159(5):454-466. [PubMed: 14977641]

5. Kelley DS. Modulation of human immune and inflammatory responses by dietary fatty acids. Nutrition July;2001 17(7-8):669-673. [PubMed: 11448594]

6. Kelemen LE, Cerhan JR, Lim U, Davis S, Cozen W, Schenk M, Colt J, Hartge P, Ward MH. Vegetables, fruit, and antioxidant-related nutrients and risk of non-Hodgkin lymphoma: a National Cancer Institute-Surveillance, Epidemiology, and End Results population-based case-control study. Am J Clin Nutr June;2006 83(6):1401-1410. [PubMed: 16762953]

7. Meydani SN, Wu D, Santos MS, Hayek MG. Antioxidants and immune response in aged persons: overview of present evidence. Am J Clin Nutr Dec;1995 62(6 Suppl):1462S-1476S. [PubMed: 7495247]

8. Frei B. Reactive oxygen species and antioxidant vitamins: mechanisms of action. Am J Med Sept; 1994 97(3A):5S-13S. [PubMed: 8085584]

9. Steinmetz KA. Vegetables, fruit, and cancer prevention: a review. J Am Diet Assoc 1996;96:10271039. [PubMed: 8841165]

10. Jacobs DR Jr, Steffen LM. Nutrients, foods, and dietary patterns as exposures in research: a framework for food synergy. Am J Clin Nutr Sept;2003 78(3 Suppl):508S-513S. [PubMed: 12936941]

11. Hodge AM, English DR, O’Dea K, Giles GG. Dietary patterns and diabetes incidence in the Melbourne Collaborative Cohort Study. Am J Epidemiol Mar;2007 165(6):603-610. [PubMed: 17220476]

12. Kolonel LN, Henderson BE, Hankin JH, Nomura AMY, Wilkens LR, Pike MC, Stram DO, Monroe KR, Earle ME, Nagamine FS. A multiethnic cohort in Hawaii and Los Angeles: baseline characteristics. Am J Epidemiol 2000;151:346-357. [PubMed: 10695593]

13. Jaffe, ES.; Harris, NL.; Stein, H.; Vardiman, JW. Pathology and genetics of tumours of haemotopoietic and lymphoid tissues. Lyon, France: IARC Press; 2001.

14. Morton LM, Turner JJ, Cerhan JR, Linet MS, Treseler PA, Clarke CA, Jack A, Cozen W, Maynadie M, Spinelli JJ, Costantini AS, Rudiger T, Scarpa A, Zheng T, Weisenburger DD. Proposed classification of lymphoid neoplasms for epidemiologic research from the Pathology Working Group of the International Lymphoma Epidemiology Consortium (InterLymph). Blood July;2007 110(2):695-708. [PubMed: 17389762]

15. Stram DO, Hankin JH, Wilkens LR, Henderson B, Kolonel LN. Calibration of the dietary questionnaire for a multiethnic cohort in Hawaii and Los Angeles. Am J Epidemiol 2000;151:358370. [PubMed: 10695594]

16. Park SY, Murphy SP, Wilkens LR, Yamamoto JF, Sharma S, Hankin JH, Henderson BE, Kolonel LN. Dietary patterns using the Food Guide Pyramid groups are associated with sociodemographic and lifestyle factors: the multiethnic cohort study. J Nutr Apr;2005 135(4):843-849. [PubMed: 15795445]

17. Sharma S, Murphy SP, Wilkens LR, Au D, Shen L, Kolonel LN. Extending a multiethnic food composition table to include standardized food group servings. J Food Composition Analysis 2003;16:485-495.

18. Morton LM, Zheng T, Holford TR, Holly EA, Chiu BC, Costantini AS, Stagnaro E, Willett EV, Dal ML, Serraino D, Chang ET, Cozen W, Davis S, Severson RK, Bernstein L, Mayne ST, Dee FR, Cerhan JR, Hartge P. Alcohol consumption and risk of non-Hodgkin lymphoma: a pooled analysis. Lancet Oncol July;2005 6(7):469-476. [PubMed: 15992695] 
19. Talamini R, Polesel J, Montella M, Dal ML, Crovatto M, Crispo A, Spina M, Canzonieri V, La VC, Franceschi S. Food groups and risk of non-Hodgkin lymphoma: a multicenter, case-control study in Italy. Int J Cancer June;2006 118(11):2871-2876. [PubMed: 16385566]

20. Tavani A, Pregnolato A, Negri E, Franceschi S, Serraino D, Carbone A, La VC. Diet and risk of lymphoid neoplasms and soft tissue sarcomas. Nutr Cancer 1997;27(3):256-260. [PubMed: 9101555]

21. Zhang SM, Hunter DJ, Rosner BA, Giovannucci EL, Colditz GA, Speizer FE, Willett WC. Intakes of fruits, vegetables, and related nutrients and the risk of non-Hodgkin's lymphoma among women. Cancer Epidemiol Biomarkers Prev May;2000 9(5):477-485. [PubMed: 10815692]

22. Skibola CF. Obesity, diet and risk of non-Hodgkin lymphoma. Cancer Epidemiol Biomarkers Prev Mar;2007 16(3):392-395. [PubMed: 17337642]

23. Chang ET, Smedby KE, Zhang SM, Hjalgrim H, Melbye M, Ost A, Glimelius B, Wolk A, Adami HO. Dietary factors and risk of non-hodgkin lymphoma in men and women. Cancer Epidemiol Biomarkers Prev Feb;2005 14(2):512-520. [PubMed: 15734980]

24. Cross AJ, Lim U. The role of dietary factors in the epidemiology of non-Hodgkin's lymphoma. Leuk Lymphoma Dec;2006 47(12):2477-2487. [PubMed: 17169793]

25. Weisburger JH. Mechanisms of action of antioxidants as exemplified in vegetables, tomatoes and tea. Food Chem Toxicol Sept;1999 37(9-10):943-948. [PubMed: 10541449]

26. De Stefani E, Fierro L, Barrios E, Ronco A. Tobacco, alcohol, diet and risk of non-Hodgkin's lymphoma: a case-control study in Uruguay. Leuk Res May;1998 22(5):445-452. [PubMed: 9652731]

27. Mussman HC. Drug and chemical residues in domestic animals. Fed Proc Feb;1975 34(2):197201. [PubMed: 1116615]

28. Purdue MP, Bassani DG, Klar NS, Sloan M, Kreiger N. Dietary factors and risk of non-Hodgkin lymphoma by histologic subtype: a case-control analysis. Cancer Epidemiol Biomarkers Prev Oct; 2004 13(10):1665-1676. [PubMed: 15466985]

29. Hu FB. Dietary pattern analysis: a new direction in nutritional epidemiology. Curr Opin Lipidol Feb;2002 13(1):3-9. [PubMed: 11790957]

30. Jinlin F, Binyou W, Terry C. A new approach to the study of diet and risk of type 2 diabetes. J Postgrad Med Apr;2007 53(2):139-143. [PubMed: 17495384]

31. Jacques PF, Tucker KL. Are dietary patterns useful for understanding the role of diet in chronic disease? Am J Clin Nutr Jan;2001 73(1):1-2. [PubMed: 11124739]

32. Alexander DD, Mink PJ, Adami HO, Chang ET, Cole P, Mandel JS, Trichopoulos D. The nonHodgkin lymphomas: a review of the epidemiologic literature. Int J Cancer 2007;120(Suppl 12):139. [PubMed: 17405121]

33. Morton LM, Wang SS, Cozen W, Linet MS, Chatterjee N, Davis S, Severson RK, Colt JS, Vasef MA, Rothman N, Blair A, Bernstein L, Cross AJ, De Roos AJ, Engels EA, Hein DW, Hill DA, Kelemen LE, Lim U, Lynch CF, Schenk M, Wacholder S, Ward MH, Hoar ZS, Chanock SJ, Cerhan JR, Hartge P. Etiologic heterogeneity among non-Hodgkin lymphoma subtypes. Blood Dec;2008 112(13):5150-5160. [PubMed: 18796628] 


\begin{tabular}{|c|c|c|}
\hline "Fat and Meat" & "Vegetables" & "Fruit and Milk" \\
\hline Meat and organ meat & All vegetables & Milk and yogurt \\
Frankfurters, sausage, and luncheon meat & All fruits & All fruits \\
White potatoes & & \\
Non-whole grains & & \\
Eggs & & \\
Cheese & & \\
\hline
\end{tabular}

Figure 1.

Food groups with the highest factor loadings for the three dietary patterns (16). 


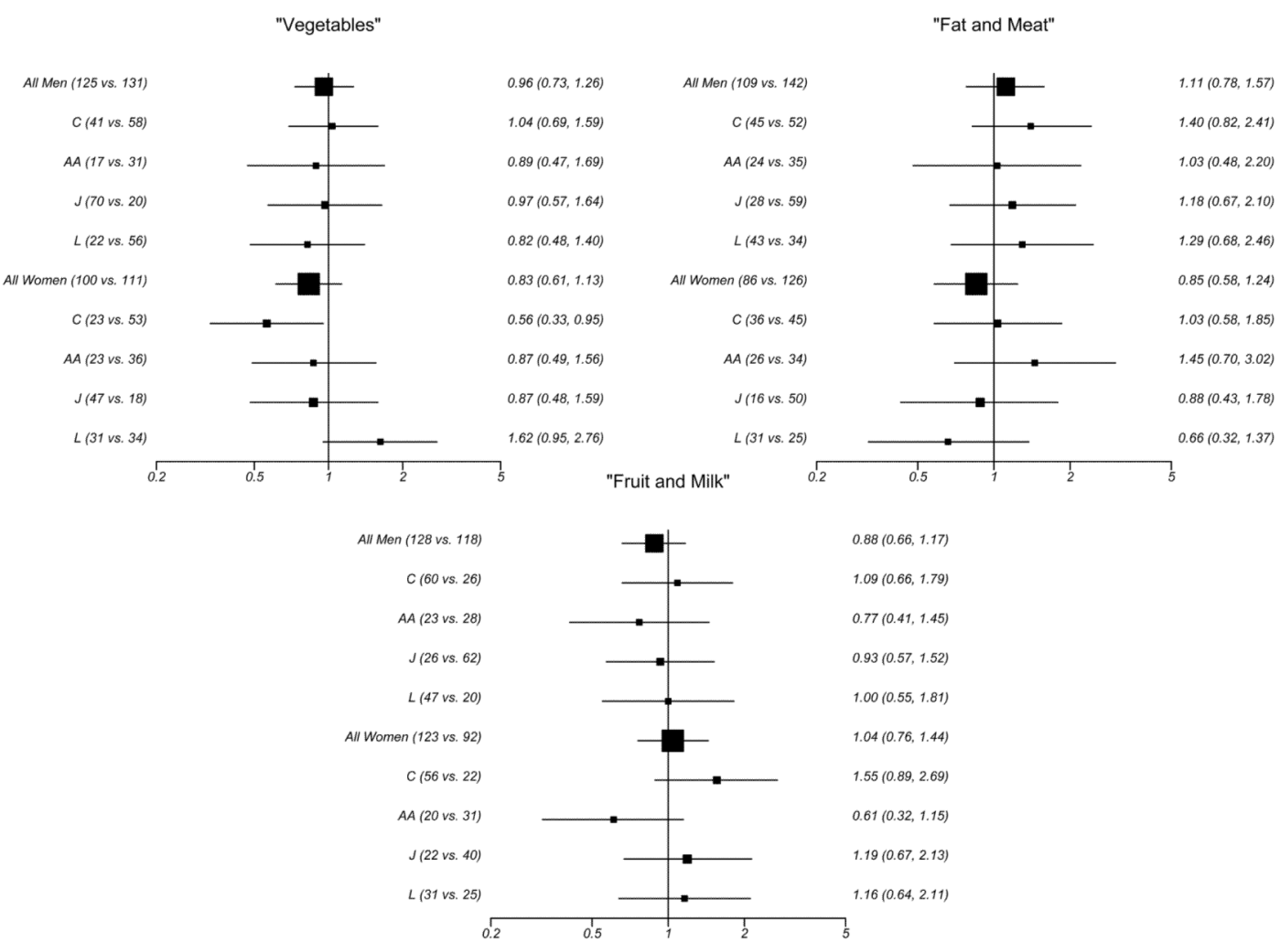

* $C=$ Caucasian, $A A=$ African-American, $J=$ Japanese $L=$ Latino; brackets represent numbers of cases in the highest tertile/quartile compared to the lowest.

Figure 2.

Non-Hodgkin Lymphoma risk for dietary patterns by ethnicity in men and women, the Multiethnic Cohort Study, 1993-2003.* 


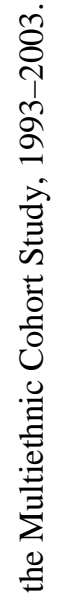

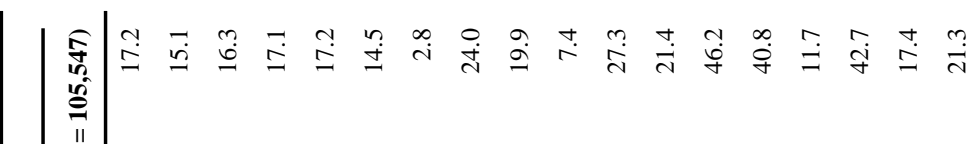

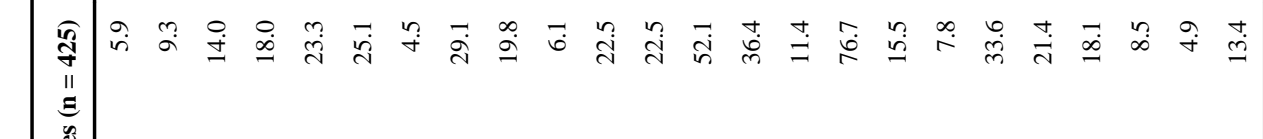

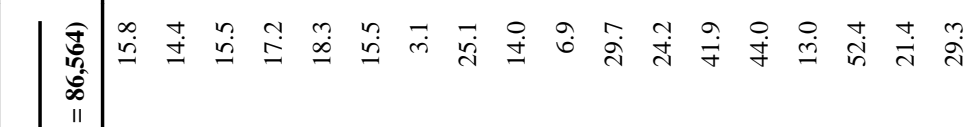




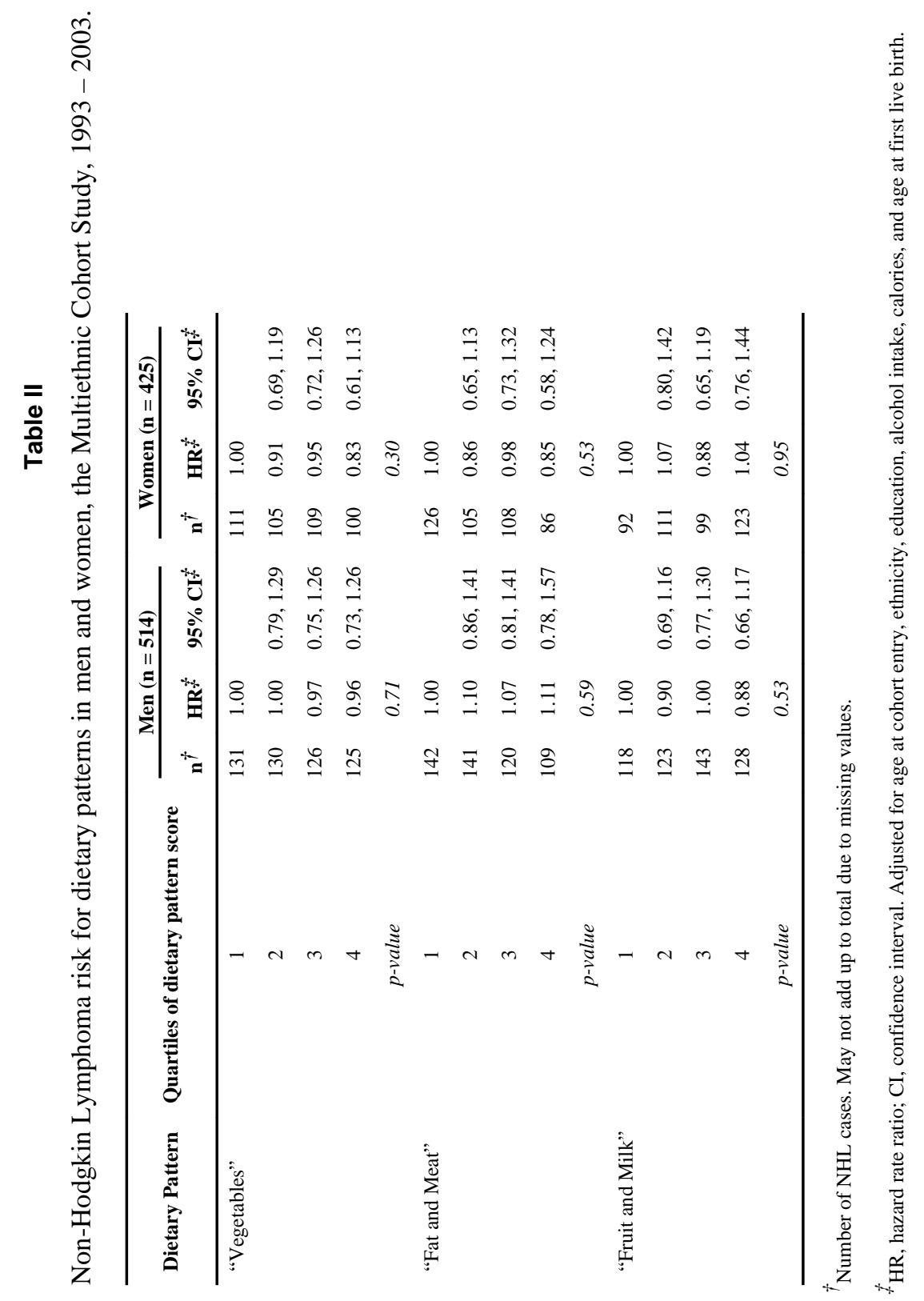




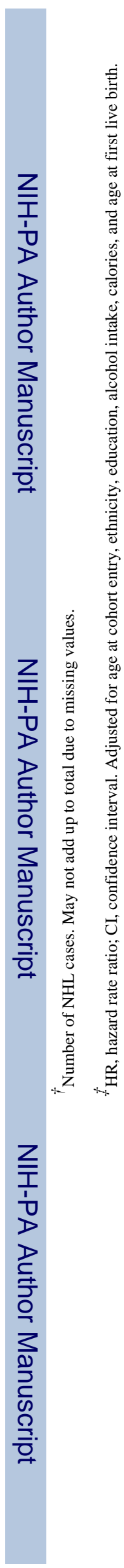

Erber et al.

Page 13

Page 13$$
\text { 政 }
$$

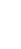
ह

$$
\text { t. }
$$$$
\text { 过 }
$$

$$
\text { 政 }
$$

$$
\text { 离 }
$$$$
\text { 푤 }
$$ 